\title{
A New Agricultural E-commerce Model Based on the Information Transmitter and Pre-sale Strategy
}

\author{
Yufeng Zhuang ${ }^{1, a^{*}}$, Hang Zhao ${ }^{1, b^{*}}$, Chi Zhang ${ }^{1, c^{*}}$ and Zilin $\mathrm{Di}^{2, \mathrm{~d}^{*}}$ \\ ${ }^{1}$ School of Automation, Beijing University of Posts and Telecommunications, Beijing, China \\ ${ }^{2}$ Institute of Art and Fashion, Tianjin Polytechnic University, Tianjin, China

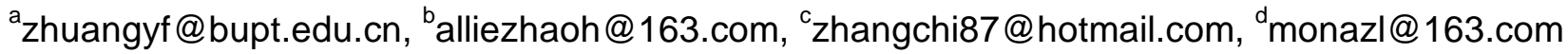 \\ * please mark the corresponding author with an asterisk
}

\begin{abstract}
Keywords: Agricultural e-commerce model, information transmitter, incentive mechanism design, pre-sale strategy

Abstract. In China, countless docking problem always exists in the agricultural production and marketing process. It often leads to blind planting and unsalable depreciated phenomena. Although the e-commerce is a good idea of exchanging supply and demand information and reducing the circulation cost, it faces up farmers lack of knowledge and their mistrust. In this paper, we present a new type of agricultural e-commerce model for the current problems. It introduces the information transmitter who comes from the village and serves local farmers. The information transmitter can establish an effective connection bridge between the individual farmer and the e-commerce network. This paper also proposes an incentive mechanism for the information transmitter and pre-sale strategy based on a tiered pricing system. After analyzing the system and the strategy the benefit of all participants can be guaranteed. This model will effectively stabilize the income of farmers and solve the docking problem.
\end{abstract}

\section{Introduction}

Agriculture is the foundation of national economy and farmers are the main body of agricultural production and operation. To ensure the healthy development of agriculture, it's important to guarantee the farmers' income. As farmers maintain their livelihoods by selling agricultural products, price fluctuation of agricultural products directly lead to great risk of farmers' lives. The development level of Chinese rural areas stays backward for a long time, causing that most farmers lack the abilities to acquire and analyze market information. Farmers often choose to grow varieties which are selling well or having high profits at present. However, as a result of long agricultural production cycle, they often find that the market has changed by the time agricultural products came mature. Hot agricultural products suddenly turn into trouble this year, which may have been hard to sell difficulty in marketing or are not on the selling price any more. The outcome of 'Herd' phenomenon in planting and agricultural bumper harvests is that the agriculture product's output become greater than consumers' demand. It leads to the decline of agricultural products' price and even make products unsalable. All of the above have made a lot of farmers a year of hard work in vain [1]. For example, a few years ago, we rarely saw vegetables called okra appeared on the public table. As the nutritional value of okra known by people gradually, more and more people begin to buy it, which makes okra's market price is soaring. Farmers took a fancy to its ultrahigh economic benefits, so they began to planted okra in large area in the past two years. As a result, okra's procurement price fell by nearly a half, from 8-9 yuan per kilogram to 4-5 yuan per kilogram [2]. From the demand side of the agricultural market, we knew that it is another problem that citizens have no choice but buy vegetables at a high price. Agricultural products should go through 'farmers - origin vendors - local wholesalers (transporters) - retailers consumers' from the field to the table. Each of these links has more than $25 \%$ of the increase, making the prices of agricultural products several times higher than the origin prices when they come to consumers [3]. To balance China's agricultural production and consumption is an urgent problem that needs to be solved. 
With the highly integration of information technology and agricultural management, we can solve the above problem with the help of e-commerce platform. E-commerce platform can break the intermediate links of the sales of agricultural products, which makes the producers and consumers get closer [4]. Through the platform, farmers can sell agricultural products to consumers all over the country, and consumers can choose high quality agricultural products all over the country with good prices. Besides, by using big data technology to analyze the agricultural market, it is possible to guide farmers to make a responsible choice of planting variety and quantity.

However, Chinese farmers are mainly the elderly at present. Most of the farmers are weak in using modern technology [5]. There are hardly to learn new things. They can't exchange information and do other related operations smoothly through the network as well. In some places, we cannot even find a single person who can use the computer in a village. The above situation has become a huge obstacle to agricultural e-commerce in rural areas. Faced with such a status, e-commerce platform of agricultural products is hard to directly copy successful modes of other industries' e-commerce platforms. Instead, we need to build a new type of rural e-commerce mode, aiming to make an efficient connection between the e-commerce platform and the farmers who are lack of the ability to take advantages of information technology.

\section{New E-commerce Model of Agricultural Products}

Although agricultural e-commerce will be a better solution to both information asymmetry of agricultural output versus demand and the problem that most of the profits of agricultural products are occupied by the dealers. However, agricultural e-commerce still needs to face that agricultural online trading websites operate each for their own camp. What's more, agricultural e-commerce is subject to the fact that the knowledge level of farmers cannot match up with the requirement of e-commerce. Accordingly, a new model has been proposed, shown in figure 1. It consists of the agricultural products' e-commerce platform which can transport agricultural information, and the logistics network which can exchange agricultural products. On one side, the e-commerce platform connects to consumers who represent the agricultural demand, on the other hand and it connects to agricultural productivity which is represented by farmers with the help of information transmitters. Besides, consumers are not just individuals, but food processing enterprises, canteens and other agricultural consumption entity. The information transmitters are a batch of people trained by the e-commerce platform and sent back to the rural areas as basic service personnel. They have a higher level of intellectual knowledge and e-commerce service capacity. What the most important is they erect an agricultural e-commerce bridge for farmers lack of modern technological knowledge. Their main responsibilities are as follows. (1) Live in the rural areas to concentrate on understanding more about the growth environment, characteristics and capacity and other information of agricultural products in their region, and put the information on the e-commerce platform. (2) Promote marketing of agricultural products through multiple media. (3) Obtain demand changes of agricultural products market through the platform, and give farmers advices about what to plant. (4) Help farmers send agricultural products to consumers through the logistics network.

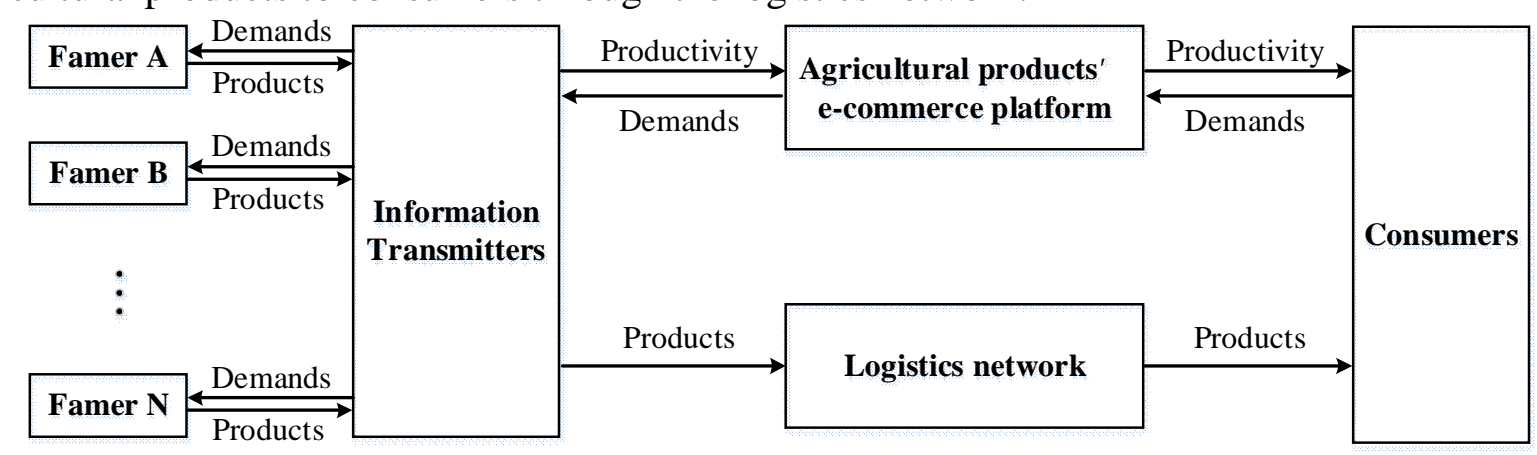

Fig. 1. New e-commerce model of agricultural products 


\section{Incentive Mechanism Design for Information Transmitters}

Information transmitter is of great importance of the new agricultural e-commerce model in this model, as he is the choke-point to the link between farmers and e-commerce platform. An information transmitter can work for several farmers and get first-hand information about the market demand. From the view of obtaining information, the information transmitter has absolute advantage compared with farmers. Therefore, it will affect the distribution of farmers' income whether the information transmitter can provide conscientious and responsible services to each farmer. This is the core issue which would affect the sustainable development of the e-commerce model proposed in this paper. Since the rural areas exist as acquaintances society, people live in the same village and the neighboring village know each other very well. As a result, information is symmetry among them. Not only are they familiar with each other's competence and personality, but also their property status and family relations. So, for choosing information transmitter, we should first consider a young person grown up in the village with basic skills and knowledge, and let him become an information transmitter after trained. The advantages have such three aspects. (1) It's easier for native information transmitter to acquire farmers' recognition, thereby reducing the cost of communication and collaboration. (2) The information transmitter serves their hometown, which makes it much easier for them to form the identification. They are more willing to help farmers in their hometown get better agricultural income through their own hard work. The sense of honor energizes them do a good job. (3) It is conducive to the prevention of corruption in the work of the information transmitter. As they need to take into account their families' long-term reputation in the village, they do not dare to accept the kickbacks or give some certain farmers high quality orders.

However, the information transmitter is an extremely important role in this model, so it is not enough that they are only bound by moral self-discipline. Penalties and rewards need to be developed to facilitate the information transmitter to make fair decisions. This model adopts the Gini coefficient of farmers' annual income per acre as a value to measure the uneven degree of information transmitters' service. The horizontal axis represents the cumulative percentage based on the household (from low to high according to the income), whereas the vertical axis represents the cumulative percentage of annual income per acre, as shown in figure 2. The curve is a 45 degree line through the origin when the cumulative percentage of the farmers' population is equal to the cumulative percentage of income, which means the farmers' income is completely equal (as shown in curve C1). In fact, the income of individual farmers is neither completely equal, nor entirely unequal, as it is in the middle of that two points. The income distribution curve is a convex curve to the horizontal axis (as shown in curve C2). $S_{\mathrm{A}}$ is the area surrounded by perfect equality curve $(\mathrm{C} 1)$ and the actual curve $(\mathrm{C} 2) . S_{3}$ is the area surrounded by the actual curve $(\mathrm{C} 2)$ and the complete inequality curve $(\mathrm{C} 3)$. Then the income Gini coefficient $\mathrm{G}$ is as follows:

$$
\mathrm{G}=\frac{s_{A}}{s_{A}+s_{E}}=\frac{\frac{1}{2}-\sum_{i=S_{n}}^{n}\left(W_{i}+W_{i+1}\right)}{\frac{1}{2}}
$$

$W_{1}$ is the proportion of the first farmer's to the each farmers' annual income per acre accounted for the sum of all farmers' annual income per acre. Finishing formula (1) obtained:

$$
\mathrm{G}=1-\frac{1}{n}\left(2 \sum_{i=1}^{n-1} w_{i}+1\right)
$$




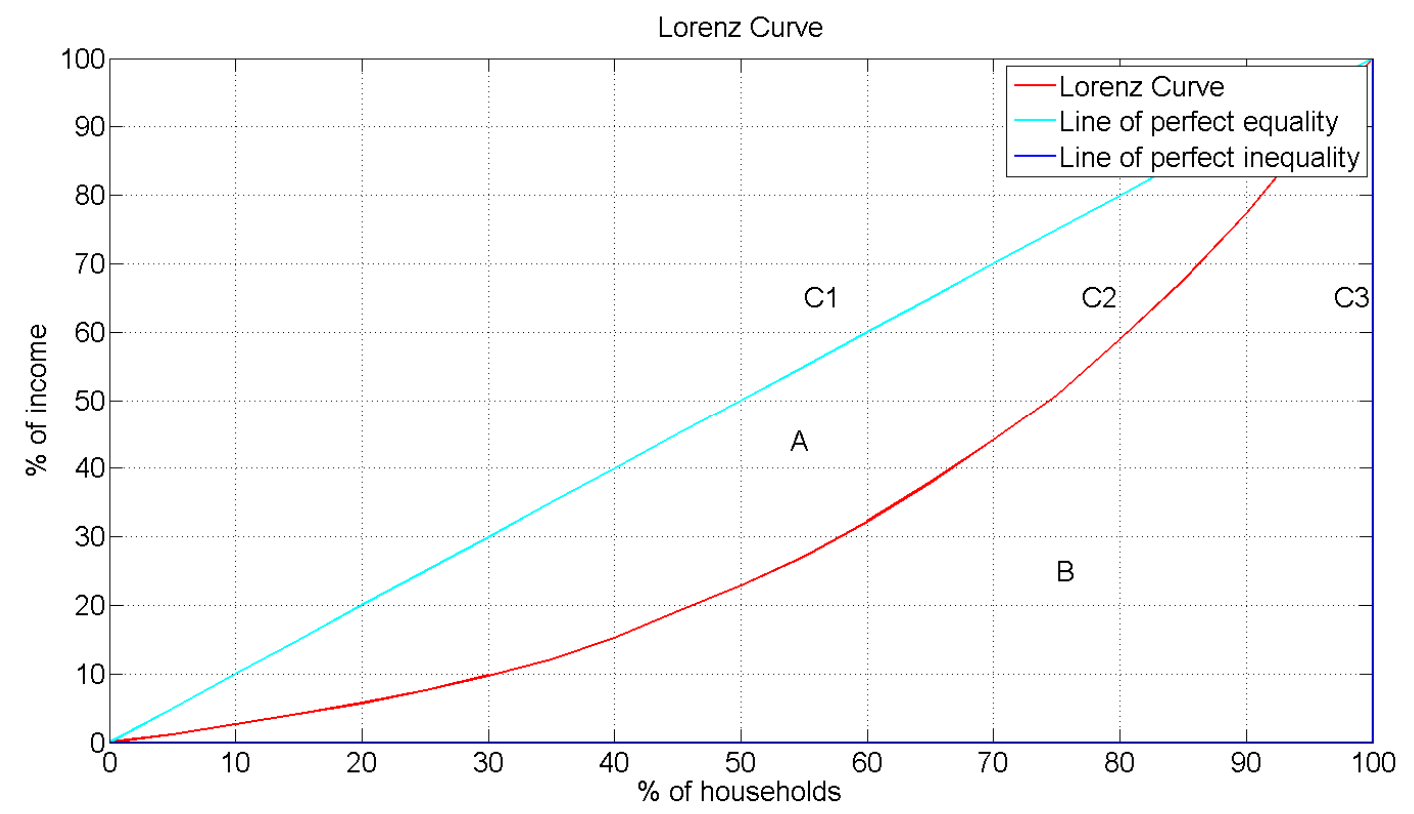

Fig. 2. Income distribution curve

We can see the income Gini coefficient $0<\mathrm{G}<1$ by the formula (2) and figure 2 . The smaller the curvature of the income distribution curve is, the smaller the Gene coefficient is. In fact, it is not realistic to be absolute equal distribution, and it is not fair at the same time. If the farmers' income is totally average, it will make the farmers become slack in work. Therefore, Gini coefficient can be used as a signal to judge whether the information transmitter is fair, which can guarantee the differences of farmers' income within a certain range by the way. We need to establish a punishment system for information transmitter according to the United Nations standards on the Gini coefficient (as shown in Table 1).

Table 1 Gini coefficient standard

\begin{tabular}{l|l}
\hline Gini coefficient & Distribution average level \\
\hline Below 0.2 & Absolutely even \\
$0.2-0.3$ & Fairly even \\
$0.3-0.4$ & Relatively reasonable gap \\
$0.4-0.5$ & Widely gap \\
above 0.5 & Extremely gap \\
\hline
\end{tabular}

When the Gini coefficient among farmers served by the same information transmitter is greater than 0.4 , the platform will give the information transmitter a warning. The information transmitter will be subject to a penalty of certain performance bonus. We will also adopt the visiting survey to investigate and publish the result public. As the information transmitter is from the village where his family is located, he will not easily be fraud and receive kickbacks in order to preserve the reputation of himself and his family.

\section{Pre-sale Strategy Based on Tiered Pricing System}

Agricultural production cycle is usually relatively long, and agricultural products are greatly influenced by the natural environment factors. To ensure steady income for farmers, the information transmitter in this model take the strategy that presell the high-quality part of the agricultural products and let the others follow the market. The strategy contains three steps. First step is to divide the same batch of agricultural products into two levels according to the quality, including high-quality and ordinary. Secondly, sell the high-quality part of agricultural products in advance, and make the sale of high-quality agricultural products cover the total cost. Last but not least, sell the ordinary part of 
agricultural products with market price. That is to say, the income of the ordinary agricultural products is farmers' net profit. This strategy ensures that farmers do not lose money after a year of work, which may promote the labor enthusiasm and labor productivity of farmers to some extent. Consumers can obtain larger premium quality in the pre-sale part, so it's more likely to complete the plan because of good quality.

Set the expected total output of agricultural products $Q$ and the quantity of high quality agricultural products $\mathrm{Q}_{\mathrm{s}}$. $\mathrm{C}$, the farmer's total production cost is composed of the following factors, $\mathrm{C}=\mathrm{C}_{0}+\mathrm{C}_{1} \mathrm{Q}+\mathrm{C}_{2} \mathrm{Q}^{2} \cdot \mathrm{C}_{0}$ is the fixed cost, it is mainly composed of the rent of agricultural implements and depreciation expense, and farmers' daily consumption which will occur anyway even they don't have production activity. Unit planting cost $C_{1}$ can be composed of $C_{P}, C_{L}$ and $C_{I}, C_{1}=C_{P}+C_{L}+C_{I}$. $C_{P}$ is the planting cost per unit of agricultural product, which are brought by the seed, fertilizer, greenhouse, irrigation and other factors. $\mathrm{C}_{\mathrm{L}}$ is the logistics cost per unit of agricultural product in the way of being sent to consumers. $C_{I}$ is the performance bonus cost for the information transmitter. $C_{2}$ is a coefficient represented the effort of farmers' planting activities, $C_{2}>0 . C_{2} Q^{2}$ is farmers' effort cost during planting activities. In conclusion, cost $\mathrm{C}$ can be expressed as:

$$
\mathrm{C}=\mathrm{C}_{0}+\left(\mathrm{C}_{\mathrm{P}}+\mathrm{C}_{\mathrm{L}}+\mathrm{C}_{\mathrm{I}}\right) \mathrm{Q}+\mathrm{C}_{2} \mathrm{Q}^{2}
$$

If the ratio of pre-sale part quantity of agricultural products $\mathrm{Q}_{\mathrm{S}}$ accounted for the total output $\mathrm{Q}$ is $\alpha$. According to the general experience, the pre-sale ratio is $1 / 3$.Then the formula among them is:

$$
\mathrm{Q}_{\mathrm{S}}=1 / 3 \mathrm{Q}
$$

To guarantee the production cost covered by income of pre-sale products, the pre-sale price $\mathrm{P}_{\mathrm{s}}$ of agricultural products should meet the following formula:

$$
\mathrm{P}_{\mathrm{s}}=\mathrm{C} / \mathrm{Q}_{\mathrm{S}}
$$

The unit price of agricultural products shall be:

$$
\mathrm{P}_{\mathrm{s}}=3\left(\mathrm{C}_{0}\right) / \mathrm{Q}+3\left(\mathrm{C}_{\mathrm{P}}+\mathrm{C}_{\mathrm{L}}+\mathrm{C}_{\mathrm{I}}\right)+3 \mathrm{C}_{2} \mathrm{Q}
$$

At this time, farmers' net profit is:

$$
\pi_{\mathrm{F}}\left(\mathrm{P}_{\mathrm{R}}\right)=\left(\mathrm{P}_{\mathrm{R}}-\mathrm{C}_{\mathrm{L}}\right)\left(\mathrm{Q}_{\mathrm{R}}-\mathrm{Q}_{\mathrm{S}}\right)-\mathrm{C}_{\mathrm{I}}\left(\mathrm{P}_{\mathrm{R}}>\mathrm{C}_{\mathrm{L}}\right)
$$

$\mathrm{Q}_{\mathrm{R}}$ is the actual output of agricultural products and $\mathrm{P}_{\mathrm{R}}$ is the market prices for agricultural products.

The pre-sale part of agricultural products is of high quality, which can ensure that farmers do not lose money and satisfy the consumers' demand for high quality agricultural products simultaneously. Later, ordinary agricultural products with market prices can ensure that consumers buy agricultural products without leaving their homes at a normal price. It meets the needs of consumers that enjoy the same quality of agricultural products at the same price but get better service. Thus, both pre-sale and post-harvest sale have a certain feasibility.

When pre-sale quantity is not enough to cover the cost of agricultural products, the information transmitter has the responsibility to publicize their agricultural products with a variety of media. If the pre-sale quantity is still not enough to cover the cost after above moves, the information transmitter should investigate its reason and consider the countermeasures in advance. He can give consumers more favorable terms or change the farmers' planting strategy at last.

\section{Conclusion}

In this paper, we propose a new type of agricultural e-commerce model based on agricultural products asymmetry problems and the difficulty that farmers' low knowledge level cannot match up with the requirement of e-commerce existing in our national conditions. The model builds a bridge between individual farmer and the e-commerce network by introducing the role information transmitter. To ensure that information transmitters can provide conscientious and responsible services 
to each farmer, this paper proposes an incentive mechanism. On one hand, the information transmitter comes from the village, which gives him more identification by serving his hometown and makes him become more moral self-discipline to maintain his reputation in rural acquaintance society. On the other hand, according to the farmers' income balance degree of similar products, we can assess the fairness degree in information transmitter's work and design a corresponding reward and punishment system. The paper also put forward a pre-sale strategy based on a tiered pricing system of agricultural products. By analyzing this strategy, we can guarantee the stability of farmers' income effectively and improve farmers' farming enthusiasm.

\section{References}

[1] ZHAO Z.l. Discussion about Agricultural E-commerce Situation and Optimization. International Conference on Management Science \& Engineering,2014:88-95.

[2] Jiang J. Price of okra fell by blind planting. JiaXing Daily ,Sep. 2015.(in Chinese)

[3] LI L.P. Study on the supply chain management of Agriculture Product under E-commerce Environment. International Conference on Intelligent Computation Technology and Automation,2009:333-336.

[4] Poole, B. How will Agricultural E-Markets Evolve. Paper Presented at the USDA Outlook Forum, Washington DC, February 22-23, 2001.

[5] Yan C, Guo S. Preliminary construction of rural e-commerce [J]. Modern Economic Information, 2008(5): 15-25. (in Chinese)

[6] Meng X.m. Studying on construction programs of the platform of agricultural E-commerce.

Workshop on Intelligent Information Technology Application, IITA 2007:354-357. 